\title{
GAMBARAN IMPLEMENTASI PROGRAM JAMINAN KESEHATAN NASIONAL DI RUMAH SAKIT IBU DAN ANAK HARAPAN BUNDA TAHUN 2016
}

\author{
Pande Made Sri Rahayu, Putu Ayu Indrayathi* \\ Program Studi Kesehatan Masyarakat Fak. Kedokteran Universitas Udayana \\ *Email:pa_indrayathi@unud.ac.id
}

\begin{abstract}
ABSTRAK
Dalam upaya mencapai Jaminan Kesehatan Semesta (Universal Health Coverage) tahun 2019 maka seluruh elemen kesehatan diharapkan dapat bekerja sama, termasuk rumah sakit RSIA Harapan Bunda sebagai salah satu fasilitas kesehatan tingkat lanjut yang bekerja sama dengan BPJS Kesehatan tercatat mulai pada bulan Maret 2015. Tujuan dari penelitian ini adalah untuk mengetahui gambaran implementasi program JKN di RSIA Harapan Bunda. Penelitian ini merupakan penelitian dengan desain deskriptif kualitatif. Pengumpulan data dilakukan dengan wawancara mendalam kepada responden yang telah ditentukan dengan metode purposive sampling sebanyak 13 orang. Hasil penelitian menunjukkan bahwa RSIA Harapan Bunda perlu persiapan dari bagian manajemen selama 6 bulan agar dapat menerima pasien JKN. Persiapan dari pembentukan tim penanggung jawab pelaksanaan JKN di rumah sakit dan sarana prasarana. Keuntungan secara nominal selama 1 tahun pelaksanaannya belum didapat hanya masyarakat semakin mengenal RSIA Harapan Bunda sehingga kunjungan pasien bertambah. Petugas medis memberikan pelayanan yang sama kepada pasien umum dan pasien pengguna JKN, berdasarkan pada SOP yang telah ditetapkan oleh rumah sakit. Petugas penunjang medis telah berbekal pelatihan tentang penggunaan program INA-CBGs di rumah sakit.Pasien sebagai penerima pelayanan kesehatan merasa sangat terbantu dengan adanya program JKN. Prosedur dalam memperoleh pelayanan kesehatan sudah diketahui, namun masih ada pasien yang belum memahami dengan baik sehingga ada kesalahpahaman dengan petugas pendaftaran rumah sakit. Sosialisasi untuk penyatuan persepsi dan komitmen dari setiap komponen rumah sakit agar seluruh karyawan dapat memahami program ini dan mengetahui hal-hal apa saja yang harus diupayakan untuk mewujudkan pelayanan kesehatan yang cost effective.
\end{abstract}

Kata Kunci: Implementasi, Jaminan Kesehatan Nasional, RSIA.

ABSTRACT

In an effort to achieve Universal Health Coverage in 2019, all health providers are expected to work together including private provider. RSIA Harapan Bunda as one of the secondary health facilities, in collaboration with BPJS Kesehatan starting in March 2015. The aim of this research was to find out the description of the implementation of the JKN program at RSIA Harapan Bunda. This research is a qualitative descriptive design research. Data collection is done by in-depth interviews with respondents who have been determined by purposive sampling method as many as 13 people. The study found that, RSIA Harapan Bunda need for 6 months in order to implement and receive JKN patients. Preparation of the establishment of a team responsible for implementing JKN in hospitals and facilities. Nominal gains during the 1 year implementation have not yet been obtained, only the community is getting to know RSIA Harapan Bunda so that patient visits increase. Medical staff provide the same service to general patients and JKN user patients, based on the SOP set by the hospital. Medical support staff have been trained in the use of the INA-CBGs program in hospitals. Patients as recipients of health services were greatly helped by the JKN program. The procedure for obtaining health services is known, but there are still patients who do not understand well so there is a misunderstanding with the hospital registration officer. Socialization to unite the perceptions and commitments of each component of the hospital so that all employees can understand this program and know what things should be sought to realize cost effective health services.

Keywords: Implementation, National Health Insurance, RSIA

\section{PENDAHULUAN}

Pembangunan kesehatan yang

dilakukan pemerintah saat ini bertujuan

untuk meningkatkan derajat kesehatan masyarakat yang setinggi-tingginya agar terwujud manusia Indonesia yang bermutu, sehat dan produktif. Derajat kesehatan yang rendah akan berpengaruh terhadap 
produktivitas kerja, yang pada akhirnya menjadi beban bagi masyarakat dan pemerintah. Pada umumnya, masyarakat miskin dan rentan mempunyai derajat kesehatan yang lebih rendah akibat sulitnya mengakses pelayanan kesehatan yang disebabkan tidak adanya kemampuan ekonomi untuk menjangkau biaya pelayanan kesehatan. Oleh karena itu pemerintah pusat dan daerah bertanggung jawab untuk memberikan jaminan kesehatan yang bertujuan untuk meningkatkan akses terhadap pelayanan kesehatan bagi masyarakat miskin dan rentan serta memberikan perlindungan keuangan atas pengeluaran kesehatan akibat sakit. Indikator-indikator kesehatan akan lebih baik apabila pelayanan kesehatan yang terkait dengan kemiskinan lebih diperhatikan (Depkes, 2008; DJSN, 2012). Dalam beberapa tahun terakhir ini, berbagai negara berusaha untuk mewujudkan jaminan kesehatan bagi seluruh penduduk atau jaminan kesehatan semesta (universal health coverage) upaya ini dimaksudkan untuk meningkatkan akses masyarakat pada pelayanan kesehatan yang komprehensif, bermutu, dan merata bagi seluruh penduduk. Indonesia bersama negara-negara anggota Organisasi Kesehatan Dunia Wilayah Asia Tenggara lainnya telah menyepakati strategi pencapaian jaminan kesehatan semesta yang mencakup langkah: 1) menempatkan pelayanan kesehatan primer sebagai pusat jaminan kesehatan semesta, 2) meningkatkan pemerataan pelayanan kesehatan melalui perlindungan sosial, 3) meningkatkan efisiensi pemberian pelayanan kesehatan, dan 4) memperkuat kapasitas pelayanan kesehatan untuk mencapai jaminan kesehatan semesta (Kemenkokesra, 2012).

Tingginya biaya pelayanan kesehatan di Indonesia merupakan masalah yang serius karena sangat membebani masyarakat pengguna jasa pelayanan kesehatan. Masalah tingginya biaya pelayanan kesehatan semakin dirasakan berat setelah krisis ekonomi tahun 1997/1998 sampai sekarang. Sejak krisis melanda Indonesia, pemerintah mengalokasikan sejumlah dana untuk membantu penyelenggaraan pelayanan kesehatan dasar, terutama untuk pelayanan penduduk miskin. (Muninjaya, 2012)

Undang-Undang Nomor 40 Tahun 2004 tentang Sistem Jaminan Sosial Nasional (SJSN) dan Undang-Undang Nomor 24 Tahun 2011 tentang Badan Penyelenggara Jaminan Sosial (BPJS) mengamanatkan semua fasilitas kesehatan untuk menyediakan pelayanan kesehatan yang bermutu, merata, dan terjangkau bagi masyarakat. Pelaksanaan program Jaminan Kesehatan Nasional (JKN) yang diselenggarakan oleh BPJS Kesehatan bertujuan untuk memberikan perlindungan kesehatan dalam bentuk pemeliharaan kesehatan guna memenuhi hak warga negara atas kesehatan.

Di era JKN rumah sakit merupakan fasilitas kesehatan rujukan tingkat lanjut yang menangani pasien rujukan dari fasilitas kesehatan tingkat pertama. Menurut Sreshthaputra dan Indratna dalam Murti (2010), untuk mencapai universal coverage, maka elemen pembiayaan kesehatan tidak dapat dipisahkan dengan implikasinya pada penyediaan pelayanan kesehatan. Setiap warga harus memperoleh kualitas yang sama baik dari pembiayaan pelayanan kesehatan serta akses terhadap pelayanan kesehatan. 
Pengguna sumber daya, baik dalam administrasi dan manajemen dana asuransi maupun efisiensi penyediaan pelayanan kesehatan harus diperhatikan. Ketanggapan sistem pembiayaan dan penyediaan pelayanan kesehatan dalam memenuhi hak dan ekspektasi warga terhadap pelayanan kesehatan harus efektif, bermutu dan dibutuhkan.

Salah satu fasilitas kesehatan yang ikut program JKN adalah Rumah Sakit Ibu dan Anak Harapan Bunda. Rumah Sakit ini terletak di Jalan Tukad Unda No. 1 Renon Denpasar. Sejak bekerjasamanya RSIA Harapan Bunda dengan pihak BPJS Kesehatan kunjungan pasien pengguna JKN mulai ada dan meningkat tiap bulannya. Kunjungan pada bulan Oktober 2015 terdapat 15 orang pasien JKN yang bersalin di RSIA Harapan Bunda dari total 38 pasien yang bersalin.

Berdasarkan hasil studi pendahuluan yang telah dilakukan tentang implementasi program JKN di Rumah Sakit Ibu dan Anak Harapan Bunda yang baru berjalan beberapa bulan memiliki beraneka penilaian dari para pelakunya, menyangkut dari manajemen rumah sakit, pemberi pelayanan medis dan non medis serta pasien sebagai penerima pelayanan. Salah satu pasien JKN di Rumah Sakit Harapan Bunda adalah seorang pegawai swasta, dia ikut JKN dari bulan Desember 2015. Ini karena peralihan dari Jamsostek ke JKN dengan BPJS Kesehatan sebagai badan penyelenggaranya. Pasien tersebut baru pertama kali menggunakan jaminan kesehatan yang dimiliki. Menurut pasien pelayanan rumah sakit tergolong cepat, tidak terdapat kesan membedakan pasien umum dan pasien dengan BPJS.
Berbeda dengan pasien yang lain, yaitu seorang ibu post partum mengatakan ikut JKN karena mendaftarkan diri dan keluarganya secara sukarela langsung ke kantor BPJS dengan memilih tanggungan kelas dua. Menurutnya menggunakan JKN memiliki sedikit kerumitan pada sistem rujukan serta beberapa persyaratan yang harus dipersiapkan terlebih dahulu untuk penanganan non emergency. Dari sisi pelayanan rumah sakit, pasien mengatakan mendapat pelayanan dengan baik.

Pasien lain mengatakan bahwa pada awalnya tidak merasakan kendala karena sudah mendapatkan pelayanan dengan baik, namun saat harus melunasi administrasi, pasien sedikit terkejut dengan biaya yang harus dibayar. Ini karena pasien naik kelas ke kelas pelayanan yang lebih tinggi, maka akan mendapat fasilitas lebih nyaman namun dengan kewajiban membayar selisih tanggungan JKN yang sesuai dengan kelasnya. Pasien merasa selisih pembayaran cukup besar dan di luar perkiraan.

Pemegang kebijakan di rumah sakit menyatakan keikutsertaan rumah sakit dalam program JKN sudah berdasarkan keputusan para pemegang saham dan dokter spesialis yang praktek di RSIA Harapan Bunda. Bila dilihat dari waktu penerapan awal JKN pada Januari 2014, keikutsertaan RSIA Harapan Bunda termasuk terlambat karena baru bergabung tercatat dari bulan Maret 2015. RSIA Harapan Bunda memerlukan kesiapan agar dapat memberi pelayanan pada pasien JKN.

Berdasarkan data-data di atas maka penulis tertarik untuk mengetahuai bagaimana implementasi program JKN di RSIA Harapan Bunda agar dapat dijadikan sebuah evaluasi dari pelaksaan awal program, sehingga dapat 
meningkatkan kualitas pelayanan dan pendapatan rumah sakit.

\section{METODE PENELITIAN}

Rancangan penelitian yang digunakan bersifat kualitatif yaitu penelitian dengan menggunakan teknik untuk memperoleh informasi mendalam tentang pendapat, persepsi atau perasaan seseorang. Penelitian ini merupakan penelitian yang digunakan untuk menggambarkan apa adanya suatu variabel, gejala atau kejadian pada suatu program atau kegiatan (Prastowo,2011) Penelitian ini dilakukan di Rumah Sakit Ibu dan Anak Harapan Bunda yang berlokasi di Jalan Tukad Unda No. 1 Denpasar. Penelitian ini dilaksanakan selama 8 minggu dimulai dari bulan AprilMei tahun 2016.

Informan dalam penelitian ini terdiri dari bagian manajemen, petugas medis dan penunjang medis serta pasien yang mendapatkan perawatan di RSIA Harapan Bunda saat penelitian berlangsung. Jumlah informan tidak menjadi faktor penentu utama dalam penelitian, akan tetapi kelengkapan data yang dibutuhkan. Asas kecukupan dan kesesuaian digunakan dalam menentukan jumlah informan. Asas kecukupan merupakan data yang diperoleh dari informan yang diharapkan dapat menggambarkan fenomena yang berkaitan dengan topik penelitian. Sedangkan asas kesesuaian berarti informan dipilih berdasarkan keterkaitan informan dengan topik penelitian (Nahrisah,2008). Bagian manajemen yang menjadi informan berjumlah 3 orang terdiri dari 1 orang direktur RSIA Harapan Bunda, 1 orang kepala bagian keuangan RSIA Harapan
Bunda, 1 orang bagian pemasaran RSIA Harapan Bunda, dari bagian pelayanan medis berjumlah 3 orang, yaitu 1 kepala bagian keperawatan, 2 orang perawat pelaksana. Bagian penunjang medis yang menjadi sampel penelitian adalah bagian rekam medis 1 orang, 1 orang dari bagian verifikator. Selain pihak yang berasal dari rumah sakit, peneliti juga melakukan wawancara mendalam pada penerima layanan JKN yaitu pasien yang diambil 5 orang pasien. Jadi total sampel yang digunakan berjumlah 13 orang (tabel 1).

Dalam pengumpulan data secara kualitatif, teknik pengambilan sampel yang digunakan adalah purposive sampling, yaitu pengambilan sampel yang didasarkan pada suatu pertimbangan tertentu yang dibuat oleh peneliti, berdasarkan ciri atau sifat-sifat populasi yang sudah diketahui sebelumnya (Notoatmojo,2010).

Data yang dikumpulkan dalam penelitian ini adalah data primer dan data sekunder. Untuk data kualitatif ketika melakukan wawancara mendalam menggunakan pedoman wawancara dan alat perekam (tape recorder). Data kualitatif dianalisa menggunakan analisa tematik, yaitu melaporkan hasil penelitian dengan menekankan pada jawaban pertanyaan penelitian, sehingga menghasilkan tematema pelaporan yang sesuai dengan pertanyaan penelitian. Adapun langkahlangkah yang dilakukan untuk menganalisa data kualitatif menurut Patilima (2011) sebagai berikut: mengorganisasikan data, koding, membandingkan permasalahan berdasarkan teori, mencari alternatif penjelasan bagi data, menulis hasil penelitian 
Tabel 1. Karakteristik responden

\begin{tabular}{|c|c|c|c|c|c|c|}
\hline No & $\begin{array}{l}\text { Kode } \\
\text { Responden }\end{array}$ & Umur & Pendidikan & Jenis Responden & Pekerjaan & Kepesertaan \\
\hline 1 & 01 & 51 thn & S1 & Manajemen & Swasta & - \\
\hline 2 & 02 & 44 thn & SMA & Manajemen & Swasta & - \\
\hline 3 & 03 & 34 thn & S1 & Manajemen & Swasta & - \\
\hline 4 & 04 & 42 thn & D IV & Petugas Medis & Swasta & - \\
\hline 5 & 05 & 28 thn & D III & Petugas Medis & Swasta & - \\
\hline 6 & 06 & 23 thn & D III & Petugas Medis & Swasta & - \\
\hline 7 & 07 & 23 thn & D I & $\begin{array}{l}\text { Petugas } \\
\text { PenunjangMedis }\end{array}$ & Swasta & - \\
\hline 8 & 08 & 29 thn & D III & $\begin{array}{l}\text { Petugas } \\
\text { PenunjangMedis }\end{array}$ & Swasta & - \\
\hline 9 & 09 & 37 thn & SMA & Pasien & IRT & Mandiri \\
\hline 10 & 10 & 21 thn & SMK & Pasien & Swasta & $\begin{array}{l}\text { Karyawan } \\
\text { Swasta }\end{array}$ \\
\hline 11 & 11 & 40 thn & SMA & Pasien & IRT & Mandiri \\
\hline 12 & 12 & 39 thn & SMA & Pasien & IRT & Mandiri \\
\hline 13 & 13 & 24 thn & SMK & Pasien & Swasta & $\begin{array}{l}\text { Karyawan } \\
\text { Swasta }\end{array}$ \\
\hline
\end{tabular}


HASIL

\section{Implementasi Program JKN dari Segi Manajemen Rumah Sakit}

Rumah sakit merupakan sebuah lembaga usaha yang padat karya yang multi disiplin, padat modal, padat teknologi, padat ilmu, padat sistem, padat tenaga, serta dipengaruhi oleh lingkungan yang selalu berubah. Berdasarkan hal tersebut manajemen dalam sebuah usaha pelayanan kesehatan memiliki sebuah peran yang penting. Manajemen dalam lingkup pelayanan kesehatan sama halnya seperti dalam manajemen perusahaan. RSIA Harapan Bunda memiliki struktur manajemen yang dipimpin oleh seorang direktur, di bawah direktur terdapat lima kepala bagian yaitu kepala bidang pelayanan keperawatan, kepala bidang pelayanan medis, kepala bagian umum, kepala bagian SDM dan kepala bagian keuangan. Direktur merupakan pengambil keputusan tertinggi di manajemen rumah sakit, terkait juga tentang keikutsertaan rumah sakit sebagai fasilitas kesehatan tingkat lanjut pada program JKN. Dalam hal ini peran direktur sangat besar.

Mengenai gambaran secara umum program JKN, berdasarkan hasil wawancara dengan bagian manajemen semua informan mengetahui tentang apa yang dimaksud program JKN, yaitu merupakan program wajib dari pemerintah berupa jaminan sosial di bidang kesehatan. Berikut kutipan wawancaranya.

"Program Jaminan Kesehatan Nasional yang merupakan program pemerintah yang tujuannya untuk menyejahterakan masyarakat di bidang kesehatan. Universal Coverage disebutnya dimana pemerintah menjamin kesehatan masyarakat secara individu.".(Informan 03)

“................, ya karena rumah sakit merupakan layanan umum yang juga harus mendukung program pemerintah oleh sebab itu karena rumah sakit kita meskipun rumah sakit swasta yang juga memberikan pelayanan kepada umum namun diwajibkan untuk ikut program JKN". (Informan 01)

Berdasarkan penilaian dari BPJS Kesehatan sebagai badan penyelenggara program JKN, RSIA Harapan Bunda sudah memenuhi persyaratan sebagai rumah sakit provider BPJS. Rumah sakit bekerjasama dengan BPJS Kesehatan diawali dari penandatanganan MoU pada bulan Maret 2016, namun dari 6 bulan sebelumnya sudah dilakukan persiapan dari bagian manajemen rumah sakit.

"Persiapan dilakukan beberapa bulan sebelum penandatanganan perjanjian dengan BPJS, sudah kurang lebih 6 bulan sebelumnya. Penandatangan perjanjian bulan Maret 2015.......". (Informan 01)

"Persiapannya karena itu kan perkiraan Maret ya jadi persiapannya sekitar 6 bulanan dari 2014 jadinya ya 6 bulan sebelum berlaku di rumah sakit". (Informan 02)

Persiapan yang sudah dilakukan sebelumnya selain persiapan secara fisik juga diperhitungkan tentang keuntungan yang mungkin didapat setelah ikut sebagai penyedia layanan kesehatan program JKN. 
“ .keuntungannya adalah emmm..... rumah sakit akan mendapat kunjungan pasien akan bertambah, karena seluruh masyarakat akan ikut program JKN, jadi kunjungan pasien akan bertambah". (Informan 01)

"Keuntungannya dari segi masyarakat semakin mengenal rumah sakit Harapan Bunda dan kita lebih dapat mempromosikan diri bahwa di rumah sakit Harapan Bunda juga dapat menangani pasien BPJS". (Informan 02)

\section{Manajemen RSIA Harapan Bunda} menyiapkan tim khusus atau penanggung jawab pelayanan peserta JKN. Terdapat sembilan penanggung jawab yang terdiri dari bagian pendaftaran dan SEP, apotek, coder, claimer, IT, keuangan, pelayanan, penunjang dan jadwal poliklinik.

"Penanggungjawab dari masing-masing bagian BPJS kami sudah bentuk, ada sekitar 9 orang. Dari tim pendaftaran, coding, kemudian tim pengklaiman, ITnya, tim keuangan, pelayanan, penunjang kemudian tim yang mengatur jadwal poliklinik, jadi ada 9 orang". (Informan 01)

"Ada tim khusus yang dibuat oleh rumah sakit, tapi dari penasehat ada direktur, ada marketing, keuangan, saya tidak ingat semua tapi ada 9 orang yang terlibat dalam tim ini.........". (Informan 03)

Peran utama bagian pemasaran adalah memasarkan atau mempromosikan rumah sakit sebagai faskes lanjutan BPJS Kesehatan sehingga faskes I dapat merujuk pasien ke
RSIA Harapan Bunda sesuai dengan fasilitas dan pelayanan kesehatan yang ada. Bagian keuangan memperhatikan tentang klaim pasien dan pembayaran dari bagian BPJS Kesehatan.

"Strategi pemasarannya untuk menjaring pasien BPJS itu kita masih tahap pemasaran di faskes I, kerja sama di faskes I yaitu di bidan-bidan praktek swasta untuk menjaring pasien BPJS. Sudah ada pasien yang datang rujukan faskes I, sudah mulai lumayan". (Informan 02)

"Pasien itu tidak memikirkan klaim, dari kita yang menentukan dari awal, ketika pasien ini dipriksa kartunya dengan SEP (Surat Egibilitas Pasien) dan bahwa dia boleh menggunakan kartunya, kemudian pasien mendapat pelayanan atau perawatan.....". (Informan 03)

Untuk pengumpulan klaim dan proses verifikasi setiap bulannya dilakukan oleh bagian keuangan dan pengumpulan data dari bagian rekam medis. Proses verifikasi dimulai di akhir bulan dengan mengumpulkan data dan berkas pasien yang menggunakan JKN selama sebulan. Pada awal bulan berikutnya dilakukan verifikasi oleh verifikator BPJS yang bertugas di rumah sakit bersangkutan. Kemudian pada akhir bulan disetorkan ke BPJS kesehatan dan bulan berikutnya pada tanggal 20 pembayaran sudah dilakukan, sesuai dengan penjelasan dari informan berikut. 
“........Misalnya pasien bulan Januari dikumpulkan, diverifikasi di bulan Februari, kemudian di Februari akhir kita melakukan klaim ke BPJS, kemudian bulan Maret akan dibayar oleh BPJS, biasanya di tgl 20 an". (Informan 03)

"Akreditasi untuk dasar sudah dilakukan tahun 2012 bulan Juni dan berakhir pada Inli 2015, saat ini sedang proses untuk mempersiapkan akreditasi versi tahun 2012. Untuk saat ini rumah sakit belum menetapkan tipe kelas karena masih dalam proses persiapan akreditasi". (Informan 01)

“Akreditasi di tahun 2012, namun untuk penetapan kelasnya belum, di BPJS kita masuk non kelas, sekarang sedang dikejar untuk akreditasi agar tidak di non kelas. Karena rumah sakit kita non kelas klaimnya sedikit, karena kita masuk rumah sakit khusus.......". (Informan 03)

Selama 1 tahun ikut dalam program JKN sebagai fasilitas kesehatan tingkat lanjutan ada kendala-kendala yang masih dihadapi, seperti kendala dari segi SDM, obat dan pasien.

“........, tipe rumah sakit, karena kami masih masuk dalam tipe non kelas jadi biaya klaim masih rendah. Kedua dari segi SDM, seperti dokter-dokter yang masih belum paham untuk menetapkan diagnosis utama dan diagnosis penunjang, dan masyarakat yang masih banyak belum mengerti tentang prosedur rujukan sehingga sering terjadi mis dengan rumah sakit". (Informan 01)

"Dari sisi keuangan kami masih kurang pengendalian dalam penggunaan obat dan alkes sehingga kami masih mengalami pembengkakan biaya di infoice pasien". (Informan 02)

Proses penyelesaian dengan melakukan koordinasi dengan pihak BPJS dan tim JKN di rumah sakit.

"Kendala yang ada sudah dicoba untuk dibicarakan dengan tim BPJS dan juga dokter-dokter spesialis untuk mendapatkan solusinya. Beberapa sudah tertangani tapi masih ada yang dalam proses untuk mendapatkan penyelesaian". (Informan 01)

\section{Implementasi Program JKN dari Sisi Pelayanan Medis}

Rumah sakit dalam memberikan pelayanan kepada pasien memerlukan kesiapan dan kerja sama dari semua pihak, baik bagian manajemen, petugas medis dan petugas non medis. Petugas medis merupakan seseorang yang memiliki kompetensi dan lisensi dalam menjalankan praktek kesehatan. Petugas medis dalam memberikan pelayanan kepada pasien sesuai dengan SOP dan clinical pathway yang ada di masing-masing rumah sakit.

Pemahaman para petugas medis tentang program JKN secara umum adalah sebuah program jaminan kesehatan yang diberikan oleh pemerintah untuk meringankan beban biaya kesehatan pada masyarakat. Berikut 
kutipan wawancara yang mendukung pernyataan tersebut.

"Yang saya ketahui tentang JKN adalah program pemerintah yang bertujuan memberikan jaminan kesehatan yang menyeluruh bagi rakyat indonesia untuk dapat hidup sehat, produktif dan sejahtera". (Informan 04)

Sebagai pelaksana pelayanan medis yang memerlukan payung hukum dalam setiap tindakan dan keputusan yang diambil seharusnya para petugas medis mengetahui dasar hukum pelaksanan program JKN. Berdasarkan Undang-Undang Nomor 40 Tahun 2004 tentang SJSN dengan tujuan untuk memenuhi kebutuhan dasar kesehatan masyarakat yang layak yang diberikan kepada setiap orang yang telah membayar iuran atau iurannya telah dibayar oleh pemerintah.

“Dasar hukum UU No 40 tahun 2004 tentang Sistem Jaminan Sosial Nasional (SJSN) untuk memberikan jaminan sosial menyeluruh bagi setiap orang dalam rangka memenuhi kebutuhan dasar hidup yang layak menuju terwujudnya masyarakat Indonesia yang lebih baik dalam bidang kesehatan". (Informan 04)

Manfaat JKN mencakup pelayanan yang bertujuan untuk promosi kesehatan, pencegahan, pengobatan, dan rehabilitasi, termasuk pelayanan obat dan bahan medis habis pakai sesuai dengan kebutuhan medis.
"Jenis pelayanan yang diberikan ada pelayanan untuk rawat inap dan rawat jalan. Karena saya perawat yang bertugas di rawat inap pasien yang saya rawat dalah pasien rawat inap yang dirawat di sini". (Informan 04)

Rumah Sakit Ibu dan Anak Harapan Bunda dalam memberikan perawatan kepada pasien sesuai dengan ketentuan yang sudah ditetapkan oleh rumah sakit (clinical pathways) dan SOP yang ada, tanpa ada membedakan pasien yang dirawat apakah pasien umum atau pasien dengan menggunakan jaminan kesehatan.

"Pelayanan yang diberikan kepada pasien semua sama dan sesuai dengan SOP yang sudah $a d a^{\prime \prime}$.(Informan 04)

"Ini karena kami melayani pasien semua sama, baik yang menggunakan jaminan atau pasien umum".( Informan 05)

Selama melaksanakan asuhan keperawatan sesuai dengan SOP dan clinical pathways yang sudah ditetapkan di rumah sakit, hampir tidak ada kendala yang dihadapi dalam merawat pasien yang ikut program JKN, hanya terkadang bingung bila kamar sesuai dengan tanggungan pasien penuh. Namun selama ini masih bisa diatasi dengan cara titip sementara pasien pada kamar dengan kelas lain sampai pasien yang di kamar kelas yang seharusnya pulang.

"Kendala dalam memberikan pelayanan ke pasien sih tidak ada, karena kita memberikan pelayanan secara umum sama ke semuanya, baik pasien umum 
atau yang menggunakan jaminan". (Informan 04)

\section{Implementasi Program JKN dari Sisi Pelayanan Penunjang Medis}

Rumah sakit sebagai salah satu sub-sistem pelayanan kesehatan menyelenggarakan dua jenis pelayanan, yaitu pelayanan kesehatan dan pelayanan administrasi. Pelayanan kesehatan meliputi pelayanan medik, penunjang medik, rehabilitasi medik, dan layanan keperawatan. Pelayanan administrasi mencakup semua jenis pelayanan yang bersifat administratif, termasuk administrasi keuangan yang fungsi utamanya dalah membantu kelancaran pelaksanaan pelayanan kesehatan.

Pemahaman petugas rekam medis tentang pengertian JKN adalah program jaminan kesehatan untuk seluruh masyarakat Indonesia yang dapat meringankan beban biaya kesehatan. Dijelaskan dari hasil wawancara berikut.

"JKN adalah program pemerintah untuk membantu masyarakat Indonesia dalam hal meringankan biaya pelayanan kesehatan di fasilitas kesehatan". (Informan 07)

Dalam menjalankan tugas sebagai rekam medis dan verifikator, para informan mendapatkan pelatihan dan mengikuti seminar untuk persiapan menerima pasien yang ikut program JKN

"Sudah pernah mengikuti pelatihan tentang INACBG's, pada Desember 2015". (Informan 08)
"Sampai saat ini untuk masalah kelengkapan data untuk klaim tidak terjadi masalah, semua data pasien lengkap sehingga proses pengklaiman berjalan dengan baik'. (Informan 07)

Hambatan yang dirasa paling sering dihadapi sebagai petugas rekam medis adalah ketepatan penulisan diagnosa utama dan diagnosa penyerta oleh dokter karena hal ini akan mempengaruhi besarnya klaim yang didapat oleh rumah sakit. Masalah lain yang dihadapi adalah dengan pasien yang belum lengkap administrasi seperti surat rujukan yang tidak dapat digunakan namun pasien tetap ingin mendapat pelayanan di rumah sakit. Menghadapi kendala yang ada dengan mendiskusikan kepada tim JKN rumah sakit. Kutipan wawancara yang menyatakan hal tersebut yaitu :

“.........Pasien banyak yang langsung datang untuk rawat inap ke rumah sakit tanpa mengambil rujukan ke fasilitas kesehatan satu/primer nya. Masalah lain yang pernah terjadi adalah pasien ngotot minta dirawat di RSIA harapan Bunda tapi surat rujukannya ke rumah sakit lain.....". (Informan 07)

\section{Implementasi Program JKN dari Sisi Pasien}

Pasien merupakan pengguna layanan kesehatan yang dalam penelitian ini berkaitan dengan kepesertaan pasien dalam program JKN. Dalam karakteristik informan terdapat dua jenis kepesertaan yaitu informan yang berasal dari karyawan swasta dan mandiri. 
Dari hasil wawancara peneliti dengan responden didapatkan bahwa pengetahuan pasien secara umum tentang program JKN cukup baik. Pasien mengetahui bahwa dengan ikut program JKN dapat meringankan beban biaya kesehatan mereka, apalagi keikutsertaan bersifat wajib jadi semua harus terdaftar.

"Program dari pemerintah untuk memudahkan mendapat pelayanan kesehatan". (Informan 09)

"Untuk meringankan beban biaya kesehatan, dibilang niki(ini) wajib jadi tiang (saya)daftar. Sebenarnya masih punya JKBM, tapi tiang(saya) takut nanti tidak bisa digunakan karena ada yang bilang BPJS itu wajib, jadi tiang(saya) daftar. Ini sudah bulan ke empat masuk JKN". (Informan 11)

Awal keikutsertaan para pasien dalam program JKN beragam, ada yang mendapat informasi lebih awal dan ada pula yang baru beberapa bulan terakhir ikut program ini. Kutipan hasil wawancaranya adalah :

"Ikut ada dari tiga bulan yang lalu, daftar sendiri di Renon, emmmmm...bulan Februari berarti karena saya baru 3 kali bayar. Saya pilih kelas 2 jadi bayar 53.500,00 per bulan". (Informan 12)

"Awalnya yang dari Jamsostek itu kan sudah terdaftar kemudian tahun 2014 berubah jadi BPJS jadi langsung dialihkan ke BPJS Kesehatan". (Informan 13)

Manfaat yang dirasakan oleh para pasien adalah meringankan beban biaya kesehatan terutama saat persalinan. Semua pasien yang diwawancara adalah pasien post partum. Pasien sudah memanfaatkan program JKN dari saat memeriksakan kehamilan sampai persalinan. Persiapan untuk calon bayi masih belum didaftarkan sebagai peserta JKN, hanya ibu dan keluarga yang ada pada kartu keluarga masingmasing.

"Manfaatnya sekarang saat persalinan bisa digunakan kartunya, jadi mengurangi pengeluaran biaya untuk rumah sakit". (Informan 09)

Secara umum semua responden mengetahui prosedur yang harus dilalui dalam memperoleh pelayanan kesehatan. Namun ada pula yang belum paham dan membawa rujukan untuk rumah sakit lain namun meminta untuk di rawat di RSIA Harapan Bunda dengan alasan rumah sakit yang tertera di surat rujukan penuh. Syarat untuk mendapat pelayanan di fasilitas kesehatan pertama sudah dapat diketahui oleh semua informan.

“Tau, bawa kartu BPJS ke faskes 1, saya di klinik Kimia Farma Diponogoro. Kalo pas persalinan ke bidan dulu, trus ke klinik diponogoro trus dikasi rujukan ke bali med, tapi di bali med penuh jadi dibawa kesini, awalnya tidak dikasi tapi saya menghubungi dokter kandungan saya dan rumah sakit menerima". (Informan 10)

Setelah memanfaatkan program JKN pada saat sakit atau melalui proses persalinan, pasien merasa terbantu dan tidak bingung memikirkan biaya persalinan. Ini dapat meringankan beban mereka dalam hal 
kesehatan dan dapat memperoleh pelayanan kesehatan yang baik.

"Memudahkan biaya persalinan dan biaya berobat saat sakit". (Informan 10)

"Merasa terbantu, dan dari awal kehamilan saya sudah merencanakan apabila tidak bisa melahirkan secara normal akan menggunakan BPJS untuk operasi". (Informan 13)

“.......Masalahnya tiang (saya) di klinik karya prima dirujuk ke wangaya, tapi disana penuh jadi tiang (saya) kesini disuruh sama dokter kandungannya tapi di pendaftaran tidak mau diterima karena bawa rujukan ke wangaya, jadi tiang (saya) telpon dokternya lagi trus dokternya telpon rumah sakit baru mau diterima". (Informan 09)

"Karena kemarin rumah sakit Bali Med penuh aja, trus pindah kesini. Kalau pelayanan rumah sakit baik kok, tidak ada masalah".(Informan 10)

\section{DISKUSI}

RSIA Harapan Bunda memiliki struktur manajemen yang dipimpin oleh seorang direktur, di bawah direktur terdapat lima kepala bagian yaitu kepala bidang pelayanan keperawatan, kepala bidang pelayanan medis, kepala bagian umum, kepala bagian SDM dan kepala bagian keuangan. Direktur merupakan pengambil keputusan tertinggi di manajemen rumah sakit, terkait juga tentang keikutsertaan rumah sakit sebagai fasilitas kesehatan tingkat lanjut pada program JKN. Dalam hal ini peran direktur sangat besar. RSIA
Harapan Bunda merupakan rumah sakit swasta yang kepemilikannya berbentuk Perseroan Terbatas (PT) dan dalam peraturan Menteri Kesehatan Republik Indonesia No. 340/Menkes/per/III/2010 tentang klasifiksi rumah sakit, RSIA Harapan Bunda termasuk klasifikasi rumah sakit khusus yang memberikan pelayanan pada satu bidang atau satu jenis penyakit tertentu, yaitu pada Kesehatan Ibu dan Anak (KIA). Bagian pemasaran memiliki tugas dalam mempromosikan rumah sakit sebagai fasilitas kesehatan tingkat lanjut khusus KIA sehingga kunjungan pasien semakin banyak dan dapat menambah keuntungan rumah sakit. Bagian keuangan akan memperhitungkan apakah secara nominal rumah sakit mendapat keuntungan dari keikutsertaan dalam program JKN atau tidak.

BPJS Kesehatan adalah badan yang menyelenggarakan program jaminan kesehatan, implementasinya telah dimulai sejak 1 Januari 2014. Dengan dasar hukumnya adalah Undang-Undang No 24 Tahun 2012 tentang Badan Penyelenggara Jaminan Sosial. Penyelenggara pelayanan kesehatan meliputi semua fasilitas kesehatan yang menjalin kerja sama dengan BPJS Kesehatan baik fasilitas kesehatan milik Pemerintah, Pemerintah Daerah, dan swasta yang memenuhi persyaratan melalui proses kredensialing dan rekredensialing. Proses kredensialing adalah proses untuk memberikan kewenangan klinis bagi tenaga kesehatan untuk melakukan tindakan klinis tertentu. Para tenaga kesehatan seperti dokter, perawat atau tenaga kesehatan 
lainnya dituntut untuk memiliki kompetensi yang adekuat (Herkuntanto,2009). Hal ini perlu dilakukan karena salah satu tonggak keselamatan pasien adalah pada akuntabilitas sumber daya manusia yang terlibat dalam layanan kesehatan.

Sebagai rumah sakit swasta yang pembiayaan operasionalnya dilakukan sendiri maka rumah sakit harus memperhitungkan untung dan rugi dalam mengikuti program JKN, namun karena mengetahui bahwa pelaksanaannya nanti juga akan diwajibkan maka semakin cepat ikut bergabung akan semakin mengetahui kendala dan dapat mencari pemecahannya.

Sebagai tim semua komponen rumah sakit harus memahami tentang konsep tarif paket dengan sistem INA-CBGs. INA-CBGs singkatan dari Indonesia Case Base Groups, merupakan sistem kodifikasi dari diagnosis akhir dan tindakan/prosedur yang menjadi output pelayanan, berbasis pada data costing dan coding penyakit mengacu pada International Classification of Diseases (ICD) yang disusun oleh WHO dengan acuan ICD10 untuk diagnosis dan ICD-9-Clinical Modifications untuk tindakan/prosedur. Tarif INA-CBGs mempunyai 1.077 kelompok tarif terdiri dari 789 kode group/kelompok rawat inap dan 288 kode kelompok rawat jalan. Pengelompokan kode diagnosis dan prosedur dilakukan dengan menggunakan grouper United Nations University (UNU Grouper). UNU Grouper adalah grouper casemix yang dikembangkan oleh UNU Malaysia (Kemenkes,2014).
Sistem pembiayaan dalam sistem INA-CBGs dimungkinkan suatu kasus atau kelompok CBG tertentu mempunyai selisih positif dan pada kasus atau kelompok kasus CBG yang sama pada pasien berbeda ataupun pada kelompok CBG lain mempunyai selisih negatif. Surplus atau selisih positif pada suatu kasus atau kelompok CBG dapat digunakan untuk menutup selisih negatif pada kasus lain atau kelompok CBG lain (subsidi silang). Sehingga pelayanan rumah sakit tetap mengedepankan mutu pelayanan dan keselamatan pasien.

Pelaksanaan program JKN di fasilitas kesehatan tingkat lanjut sebaiknya memiliki sebuah tim yang dapat menggerakkan, membantu melakukan sosialisasi, monitoring dan evaluasi dari implemetasi program JKN di rumah sakit. Menurut Peraturan Menteri Kesehatan RI No 27 tahun 2014 disebutkan tim case-mix/tim INA-CBG Rumah sakit. Bagian pemasaran dan keuangan memiliki peran yang khusus dalam pelaksanaan program JKN, ini berkaitan dengan keuntungan secara nominal yang didapat rumah sakit bila ikut sebagai provider BPJS kesehatan. Dalam BPJS Kesehatan (2013) fasilitas kesehatan tingkat lanjut terdiri dari : RSU, RSUP, RSUD, RS umum TNI/Polri, RS umum swasta, RS khusus (jantung, kanker, paru, mata, bersalin, kusta, jiwa dan lainya yang telah terakreditasi), RS bergerak, RS lapangan dan balai kesehatan khusus (paru, mata, KIA dan jiwa). RSIA Harapan Bunda 
termasuk dalam rumah sakit khusus KIA (Kesehatan Ibu dan Anak).

Berdasarkan Peraturan Menteri kesehatan RI No 27 Tahun 2014, meningkatkan efisiensi dan melakukan standarisasi merupakan hal yang sebaiknya dilaksanakan oleh rumah sakit sebagai pelaksana program JKN. Efisiensi dilakukan pada sisi proses seperti penggunaan sumber daya farmasi, alat medik habis pakai, lama rawat dan pemeriksaan penunjang yang secara umum merupakan area profesi, namun juga dari segi input seperti perencanaan dan pengadaan barang dan jasa yang umumnya menjadi area/tanggung jawab manajemen. Sisi proses umumnya lebih menekankan pada aspek efektifitas sedangkan sisi input umumnya lebih menekankan aspek efisiensi. Keduanya harus mampu berinteraksi untuk menghasilkan produk pelayanan yang cost effective. Sisi proses dalam hal melakukan efisiensi juga harus mampu mengurangi atau bahkan menghilangkan pelayanan yang berlebih dan tidak diperlukan (over treatment dan atau over utility). Seperti penggunaan/pemilihan obat yang berlebihan dan pemeriksaan penunjang yang tidak selektif dan tidak kuat indikasinya. Dalam pembiayaan kesehatan dikenal dengan nama Supplier Induced Demand. Istilah ini menggambarkan suatu keadaan seorang dokter/ tenaga medis menetapkan demand pasiennya dengan cara tidak berbasis pada kebutuhan. Patut ditekankan bahwa keadaan ini bukan suatu "over-treatment". Supplier Induced Demand terjadi akibat tidak seimbangnya informasi yang ada pada dokter dengan pasiennya (Rice 1998). Dokter meningkatkan demand pasiennya berbasis pada motivasi ekonomi untuk meningkatkan pendapatannya. Folland dkk (2001), memberikan suatu pernyataan bahwa supplier induced demand adalah penyalahgunaan hubungan dokterpasien oleh dokter dalam usaha memperoleh keuntungan pribadi dokter. Supplier induced demand terutama terjadi pada sistem pembayaran fee-for-service.

Efisiensi juga harus dilakukan pada biaya umum seperti penggunaan listrik, air, perlengkapan kantor dan lain-lain. Inefisiensi pada sisi input maupun proses akan berpengaruh pada ongkos/biaya produksi pelayanan rumah sakit yang mahal. Berdasarkan hal tersebut RSIA Harapan Bunda dapat melakukan evaluasi untuk dapat lebih meningkatkan efisiensi sehingga masalah penyediaan obat dapat diatasi. Melakukan standarisasi juga merupakan salah satu hal yang dapat dilakukan, perlu dibuat formularium rumah sakit (perencanaan), perlu dibuat standar pengadaan obat rumah sakit (e-katalog dan atau lelang), standar penulisan resep misal dokter hanya menulis nama generik sedangkan obat yang diberikan berdasar hasil/perolehan pengadaan. Sedangkan bila masalah pasien atau dokter-dokter yang belum memahami prosedur pelayanan JKN perlu sosialisasi dan informasi yang benar dari badan penyelenggaran JKN atau dari BPJS Kesehatan agar pelaksanaan pelayanan kesehatan dapat berjalan dengan baik.

Ditinjau dari pelayanan medis, dalam menjalankan tugasnya para dokter, 
bidan dan perawat telah menjalankan sesuai dengan SOP atau clinical pathways yang telah ditentukan sebagai sebuah standar pelayanan di rumah sakit. Clinical pathwasy adalah konsep perencanaan pelayanan terpadu yang merangkum setiap langkah kepada pasien berdasarkan standar pelayanan medis, standar asuhan keperawatan dan standar pelayanan kesehatan lainnya (Rivani,2009). Rumah Sakit Ibu dan Anak Harapan Bunda dalam memberikan perawatan kepada pasien sesuai dengan ketentuan yang sudah ditetapkan oleh rumah sakit (clinical pathway) dan SOP yang ada, tanpa ada membedakan pasien yang dirawat apakah pasien umum atau pasien dengan menggunakan jaminan kesehatan. Selanjutnya jika ditinjau dari sisi pelayanan penunjang medis seperti rekam medis, setiap pasien yang mendapat pelayaan medis tercatat pada rekam medis rumah sakit. Seusai dengan Permenkes No. 269/ Menkes/Per/III/2008, rekam medis merupakan suatu berkas yang berisikan catatan dan dokumen tentang identitas pasien, pemeriksaan, pengobatan, tindakan, dan pelayanan lain yang telah diberikan kepada pasien (Depkes RI, 2008). Berdasarkan hal tersebut, tujuan dari pengisian rekam medis adalah untuk menunjang tercapainya tertib administrasi dalam upaya peningkatan pelayanan kesehatan di rumah sakit (Wijono, 2000). Petugas rekam medis memiliki peranan penting dalam pelaksanaan program JKN, ini karena dalam pengklaiman berdasarkan kesesuaian diagnosis dan prosedur pada tagihan dengan kode ICD 10 dan ICD 9 CM (dengan melihat buku ICD 10 dan ICD 9 CM atau softcopy-nya).

Pada setiap rumah sakit yang bekerjasama dengan BPJS Kesehatan terdapat petugas verifikator. Untuk menjalankan tugasnya dalam melakukan verifikasi klaim, verifikator wajib memastikan kesesuaian diagnosis dan posedur pada tagihan dengan kode ICD 10 dan ICD 9 CM. Ketentuan koding mengikuti panduan koding yang terdapat dalam Juknis INA-CBGs (BPJS Kesehatan, 2014). Dalam menjalankan tugas sebagai rekam medis dan verifikator, para informan mendapatkan pelatihan dan mengikuti seminar untuk persiapan menerima pasien yang ikut program JKN. Pengumpulan data pasien sebagai syarat pengklaiman dilakukan dengna lancar, belum ditemukan masalah yang serius. Berbeda dengan hasil penelitian Sunarto, 2011, pada penelitian ini kendala pencairan klaim terjadi karena harus disesuaikan dengan mekanisme keuangan daerah (Sunarto, 2011).

Selanjutnya dari sisi peserta, diketahui bahwa terdapat dua jenis kepesertaan di RSIA Harapan Bunda yaitu informan yang berasal dari karyawan swasta dan mandiri. Berdasarkan Peraturan Presiden RI No. 12 tahun 2013 tentang Jaminan Kesehatan Nasional pasal 2, disebutkan bahwa peserta jaminan kesehatan terdiri dari 2 kelompok, yaitu Penerima Bantuan Iuran (PBI) dan bukan PBI. Manfaat Jaminan Kesehatan Nasional 
terdiri atas 2 (dua) jenis, yaitu manfaat medis berupa pelayanan kesehatan dan manfaat non medis meliputi akomodasi dan ambulans. Manfaat Jaminan Kesehatan Nasional mencakup pelayanan promotif, preventif, kuratif, dan rehabilitatif termasuk pelayanan obat dan bahan medis habis pakai sesuai dengan kebutuhan medis. Manfaat pelayanan promotif dan preventif meliputi pemberian pelayanan penyuluhan kesehatan, imunisasi dasar, Keluarga Berencana dan skrining kesehatan. Salah satu pasien dalam penelitian ini memanfaatkan pelayanan keluarga berencana (tubektomi), dan hampir semua memanfaatkan pelayanan JKN untuk mengurangi beban biaya persalinan.

\section{SIMPULAN}

Manajemen RSIA Harapan Bunda memulai kerja sama dengan BPJS Kesehatan pada bulan Maret 2015, bagian manajemen yang terdiri dari direktur, bagian pemasaran dan keuangan belum memahami sistem INA-CBGs dengan baik sehingga pelaksanaan program JKN di rumah sakit belum memberikan keuntungan dan masih menghadapi kendala. Petugas medis memberikan pelayanan yang sama kepada pasien umum dan pasien pengguna JKN, berdasarkan pada SOP/clinical pathway yang telah ditetapkan oleh rumah sakit. Petugas penunjang medis telah berbekal pelatihan tentang penggunaan program INA CBGs di rumah sakit, memahami prosedur pasien yang menggunakna JKN dan memasukkan diagnosis pasien sesuai dengan pedoman ICD 9 dan 10. Pasien sebagai penerima pelayanan kesehatan merasa sangat terbantu dengan adanya program JKN ini, mereka mengetahui bahwa program ini diwajibkan sehingga melakukan pendaftaran secara lngsung ke kantor BPJS, walaupun ada pula yang didaftarkan dari tempat mereka bekerja. Prosedur dalam memperoleh pelayanan kesehatan sudah diketahui, namun ada pula pasien yang belum memahami dengan baik sehingga ada kesalahpahaman dengan petugas pendaftaran rumah sakit.

Implementasi JKN di rumah sakit sebaiknya dilakukan dengan benar dan penuh tanggunggung jawab dari semua pihak. Sebaiknya rumah sakit tidak memberikan pelayanan dengan mutu yang kurang baik, seperti memperpendek jam pelayanan poliklinik, pelayanan yang bisa diselesaikan dalam waktu satu hari dilakukan pada hari yang berbeda, tidak melakukan pemeriksaan penunjang yang seharusnya dilakukan, tidak memberikan obat yang seharusnya diberikan, serta membatasi jumlah tempat tidur yang tersedia di rumah sakit untuk peserta JKN.

\section{DAFTAR PUSTAKA}

Bappenas. (2013). Rencana Pembangunan Jangka Menengah Nasional 2010-2014. Jakarta.

BPJS Kesehatan. (2013). Panduan Layanan Bagi Peserta BPJS Kesehatan. Jakarta

BPJS Kesehatan. (2014). Perubahan Tarif INA-CBG's Membuat Biaya Kesehatan Lebih Efektif. Info BPJS Kesehatan. 
Edisi VIII. Tahun 2014, BPJS Kesehatan. Jakarta

Depkes RI. (2008); DJSN (2012). Sejarah Kesehatan Nasional Jilid I. Jakarta: Depkes RI

Kellog,W.K. (2004). Logic Model Development Guide. Michigan: WK Kellogg Foundation

Kemenkes. (2014). Peraturan Menteri Kesehatan Republik Indonesia Nomor 28 Tahun 2014 Tentang Pedoman Program Jaminan Kesehatan Nasional. Jakarta

Muninjaya. (2012). Manajemen Mutu Pelayanan Kesehatan. Jakarta: Penerbit Buku Kedokteran EGC

Murti, B. (2010). Strategi untuk Mencapai Cakupan Universal Pelayanan Kesehatan di Indonesia. Temu Ilmiah Reuni Akbar FK-UNS, 27/11, 2010. Fakultas Kedokteran Universitas Sebelas Maret, Surakarta: 8.

Nahrisah, P. (2008). Evaluasi Pelaksanaan Program Terapi Rumatan Metadon di puskesmas Kecamaatan Tanjung Priuk Tahun 2008. Universitas Indonesia.

Rivani, R. (2009). Indonesia Diagnosis Related Group's. Kesmas, 4 (1) : 3-9

Satori dan Komariah. (2013). Metode Penelitian Kualitatif. Bandung : Alpabeta

Sunarto. (2011). Sistem Pembiayaan dan Skema Kelembagaan Jaminan
Kesehatan Daerah. Jogjakarta. Jurnal Kesehatan Masyarakat Nasional, 5 (6) 